\title{
Sensitivity of Bipolaris oryzae Isolates Pathogenic on Cultivated Wild Rice to the Quinone Outside Inhibitor Azoxystrobin
}

\author{
Claudia V. Castell-Miller ${ }^{1, \dagger}$ and Deborah A. Samac ${ }^{2}$ \\ ${ }^{1}$ Department of Plant Pathology, University of Minnesota, St. Paul, MN 55108 \\ ${ }^{2}$ United States Department of Agriculture-Agricultural Research Service, Plant Science Research Unit and Department of Plant \\ Pathology, University of Minnesota, St. Paul, MN 55108
}

\begin{abstract}
The occurrence of fungal brown spot, caused by Bipolaris oryzae, has increased in cultivated wild rice (Zizania palustris) paddies in spite of the use of azoxystrobin-based fungicides. The active ingredient blocks electron transfer at the quinone outside inhibitor (QoI) site in the mitochondrial cytochrome $b$ within the $b c 1$ complex, thus obstructing respiration. The in vitro averaged $\mathrm{EC}_{50}$ of baseline isolates collected in 2007 before widespread fungicide use was estimated to be 0.394 $\mu \mathrm{g} / \mathrm{ml}$ with PROBIT and $0.427 \mu \mathrm{g} / \mathrm{ml}$ with linear regression analyses. Isolates collected during 2008, 2015, and 2016 had a range of sensitivity as measured by relative spore germination (RG) at a discriminatory dose of $0.4 \mu \mathrm{g} / \mathrm{ml}$ azoxystrobin. Isolates with a higher $(\geq 80 \%)$ and lower

with QoI fungicide resistance. Two Group I introns were found in the QoI target area. The splicing site for the second intron was found immediately after the codon for G143. A mutation for fungicide resistance at this location would hinder splicing and severely reduce fitness. B. oryzae expresses an alternative oxidase in vitro, which allows the fungus to survive inhibition of respiration by azoxystrobin. This research indicates that B. oryzae has not developed resistance to QoI fungicides, although monitoring for changes in sensitivity should be continued. Judicious use of QoI fungicides within an integrated disease management system will promote an effective and environmentally sound control of the pathogen in wild rice paddies.
\end{abstract} RG $(\leq 40 \%)$ had the wild type nucleotides at amino acid positions F129, G137, and G143 of cytochrome $b$, sites known to be associated
Keywords: $\mathrm{EC}_{50}$, alternative oxidase, cytochrome $b$
Fungal brown spot (FBS), caused by Bipolaris oryzae (Breda de Haan) Shoemaker, is the most devastating disease affecting American wild rice (Zizania palustris L.) (Johnson and Percich 1992). Symptoms usually appear on aerial leaves in spring as small purple-brown lesions that frequently enlarge into elongated oval cigar-shaped lesions with a tan to brown necrotic center often surrounded by a chlorotic halo. When disease is severe, the lesions coalesce, occupy large areas in leaves, and infection may cause leaf death. Stems are weakened by infection and frequently break, causing considerable kernel loss. The fungus is thought to overwinter in infected residue that has not been burned, buried in soil, or is not in contact with water (Brantner 1995).

Wild rice has been cultivated in paddies in Minnesota since the 1950s (Oelke 2007). To reduce losses from diseases, growers implemented an integrated disease management (IDM) program that includes elimination of infected residue, use of cultivars with improved disease resistance, adequate crop fertilization, fall flooding of paddies, and application of fungicides once or twice in the season

\section{${ }^{\dagger}$ Corresponding author: C. V. Castell-Miller; caste007@umn.edu}

Mention of trade names or commercial products in this publication is solely for the purpose of providing specific information and does not imply recommendation or endorsement by the U.S. Department of Agriculture. USDA is an equal opportunity provider and employer.

Funding: The United States Department of Agriculture-Agricultural Research Service provided financial support for this research. The Minnesota Department of Agriculture and a bequest from the Imle family provided financial support.

*The $\boldsymbol{e}$-Xtra logo stands for "electronic extra" and indicates that one supplementary figure and four supplementary tables are published online.

The author(s) declare no conflict of interest.

Accepted for publication 19 February 2019.

() 2019 The American Phytopathological Society to reduce disease severity in the upper part of the canopy. However, widespread disease and reductions in grain yield occurred in 2013 , 2014, and especially in 2015, where losses exceeded 33\% (Minnesota Wild Rice Council, personal communication). These epidemics warranted investigation of the causes of the disease outbreaks, including determining if the most commonly found pathogen, $B$. ory$z a e$, could have developed resistance toward the active ingredients in the fungicides used on wild rice. The most frequently used fungicides contain the active ingredient azoxystrobin, a methoxy-acrylate belonging to the strobilurin group 11 (Fungicide Resistance Action Committee, FRAC) of the outer Quinol oxidation Inhibitors (QoI). Azoxystrobin has activity against a broad range of fungal and oomycete species pathogenic on a variety of crops (Bartlett et al. 2002; Gisi et al. 2002). Fungicides with this active ingredient were approved for use in wild rice in 2006.

The QoI fungicides inhibit mitochondrial respiration at the mitochondrial cytochrome $b c 1$ complex by binding to the ubiquinol oxidizing outer pocket (Sierotzki 2015) of the cytochrome $b$ gene (complex III), blocking electron flow between cytochrome $b$ and cytochrome $c 1$ and halting ATP production, which leads to energy deficiency and ultimately to fungal death (Wood and Hollomon 2003). Development of resistance and reduced sensitivity to these fungicides depends on fungal biology, the cytochrome $b c 1$ gene structure of the pathogen, and the agronomic context of the crops where the fungicides are applied (Sierotzki 2015). Fungi have adapted to QoI fungicides in at least in three ways: DNA mutations in the target site, expression of an alternative terminal oxidase (AOX) enzyme, and efflux of the active ingredients from fungal cells. Mutations at the cytochrome $b$ target site that change amino acid composition at or around positions 120 to $155-160$ and consequently binding configuration have been identified in a variety of fungal species (FernándezOrtuño et al. 2010; Grasso et al. 2006). Three amino acid changes have been described: glycine to alanine at position 143 (G143A), phenylalanine to leucine at site 129 (F129L), and glycine to arginine at 137 (G137R) (Gisi et al. 2002; Grasso et al. 2006; Sierotzki 2015). The G143A mutation is the most common and significant in fungicide resistance by strongly reducing binding of the QoI molecule linker and making mutants resistant to azoxystrobin (Sierotzki 
2015). Significantly, a number of fungi have an intron similar to intron bi 2 of Saccharomyces cerevisiae, directly after that position. A nucleotide substitution in codon 143 would prevent splicing of the intron leading to a deficient cytochrome $b$ (Vallières et al. 2011). Fungi such as Alternaria alternata, Blumeria graminis, Magnaporthe grisea, Mycosphaerella graminicola, M. fijiensis, Venturia inaequalis, and Plasmopara viticola lack this intron and have developed resistance to QoI fungicides (Grasso et al. 2006). While the mutation F129L is found less frequently and has less impact on resistance, it is also assumed to have a negative effect on fungal fitness (Sierotzki 2015). In Alternaria solani, the F129L mutation makes mutants about 10-fold less sensitive to azoxystrobin (Pasche et al. 2005), although disease control is attained by higher fungicide concentrations (Pasche et al. 2004). The same nucleotide alteration in Pyrenophora teres and $P$. tritici-repentis increases tolerance to the QoI fungicides (Sierotzki et al. 2007).

A second mechanism of resistance involves expression of an alternative oxidase (AOX) enzyme, that while less efficient than cytochrome $b$, provides a strobilurin-insensitive pathway for NADH oxidation (Joseph-Horne et al. 2001; Wood and Hollomon 2003). Many fungal species are less sensitive to strobilurins in in vitro assays due to AOX activity but not in vivo (Olaya and Köller 1999; Ziogas et al. 1997). In other fungi, the role of AOX during plant infection is less clear. AOX mutants of Magnaporthe grisea were pathogenic on barley leaves, but they did not cause symptoms under the oxidative stress imposed by the fungicide in contrast to the wild type isolate which still produced small lesions (Avila-Adame and Köller 2002). Field isolates of Mycosphaerella graminicola resistant to azoxystrobin that did not have the G143A mutation were poorly controlled in planta by low doses of the active ingredient. AOX was suggested to have a role in fungal survival, which could increase the likelihood for development of resistance to QoI fungicides (Miguez et al. 2004). AOX can protect some fungi from azoxystrobin in planta during early colonization stages, but it appears ineffective during spore germination, a more energy demanding stage (Wood and Hollomon 2003).

Increased transporter efflux of the active ingredients has also been proposed as a third possible mechanism for reducing sensitivity to QoI fungicides (Reimann and Deising 2005).

Determining the sensitivity of a pathogen population that has not been exposed to a fungicide (baseline isolates), or has had minimal exposure to the intended fungicide, is important for monitoring changes in sensitivity after repeated use of a chemical with a single mode of action (Hollomon 2015). B. oryzae is highly prolific, polycyclic, and genetically diverse (Ahmadpour et al. 2017; CastellMiller and Samac 2012), putting it at risk for developing resistance to QoI fungicides. Although Bipolaris maydis and Cochliobolus carbonum, which are closely related to $B$. oryzae, are considered of low risk for resistance to QoI fungicides due to the presence of an intron after the codon for glycine at position 143 (Sierotzki 2015; Stammler 2012), the structure of cytochrome $b$ in B. oryzae is not known, nor the sensitivity to azoxystrobin. The objectives of this research were to: (i) determine the $\mathrm{EC}_{50}$ of azoxystrobin for a baseline population of $B$. oryzae, (ii) screen a collection of field isolates collected from wild rice paddies for sensitivity to azoxystrobin, (iii) sequence the portion of the cytochrome $b$ gene important in fungicide resistance, and (iv) investigate whether field isolates of $B$. oryzae have an active AOX pathway when the fungus is challenged by azoxystrobin.

\section{Materials and Methods}

Fungal collections. All B. oryzae isolates were isolated from lesions on wild rice plants collected in northern locations in Minnesota during 2007, 2008, 2015, and 2016. The set of 16 isolates from 2007 was collected from wild rice plants in unspecified sites near Moose Lake (Carlson County) and at Palisade and Shovel Lake (Aitkin County), where to our knowledge, no azoxystrobin had been applied prior to that time, and thus this small set was used as the "baseline" population (henceforth named baseline). The 2008 group was isolated from wild rice cultivated at Grand Rapids, Gully, Waskish, Lake of the Woods, and Aitkin (Castell-Miller and Samac 2012).
In 2015 another collection of B. oryzae was made after an FBS epidemic on cultivated wild rice from paddies in Aitkin, Waskish, Gully, and Clearbrook. In 2016, isolates were obtained at the same locations from wild rice plants in fungicide trials at the end of the growing season. In 2015 and 2016, plants had been treated with fungicides containing azoxystrobin alone or in combination with propiconazole one or two times during the growing season. Procedures for isolation of fungi from plant tissue have been described previously (Castell-Miller and Samac 2012).

Spore production. The isolates were stored on sterile filter paper disks at $4^{\circ} \mathrm{C}$. For spore germination experiments a single disk of a test isolate was placed on $1.5 \%$ water agar for 3 to 4 weeks at $23^{\circ} \mathrm{C}$ $\left( \pm 2^{\circ} \mathrm{C}\right)$ under ambient room light. Spores were collected by adding sterile water to individual plates, and gently rubbing the surface of the agar with an autoclaved rubber policeman spatula. Concentrations of $1 \times 10^{5}$ conidia/ml were used in the experiments.

Evaluation of in vitro spore germination of B. oryzae with and without SHAM. Preliminary results showed that the fungus could have an active AOX pathway because it germinated in vitro at high doses of azoxystrobin without salicylhydroxamic acid (SHAM), an AOX pathway inhibitor.

The SHAM concentration to be used in azoxystrobin experiments was determined by assessing its effect on spore germination without azoxystrobin. SHAM (Sigma-Aldrich, St. Louis, MO) was dissolved in $100 \%$ methanol to a stock concentration of $100 \mathrm{mg} / \mathrm{ml}$. Three concentrations $(50,100$, and $150 \mu \mathrm{g} / \mathrm{ml})$ were prepared in petri dishes containing $1.5 \%$ water agar (DB Bacto agar, Bacto, Dickinson and Company, Sparks, MD). Four B. oryzae isolates: TG12Lb2 (Aitkin, MN) collected in 2008, and TG1_L2_E-1 (Aitkin, MN), PI_22_L2_ H-1 (Gully, MN), and RR_34_L1 (Waskish, MN) collected in 2015 were tested. The percent germination of 100 spores was determined for each of three replicates using a stereo-microscope. A control without SHAM was used in the experiment. A conidium was considered germinated when the hypha was at least two times the length of the conidium and had penetrated the agar at 17-18 $\mathrm{h}$ after plating. Data were analyzed using one-way ANOVA and Tukey-Kramer HSD at $P=0.05$ (JMPPro software version 13.0.0).

Experiments at different azoxystrobin concentrations were conducted with and without SHAM. Technical grade azoxystrobin (95\% active ingredient) was provided by Syngenta Crop Protection and was dissolved in $100 \%$ acetone to a stock concentration of $10 \mathrm{mg} / \mathrm{ml}$. Twofold azoxystrobin dilutions $(5,2.5,1.25,0.625$, $0.313,0.156$, and $0.078 \mu \mathrm{g} / \mathrm{ml}$ ) and a control without the chemical were prepared in $1.5 \%$ water agar with $100 \mu \mathrm{g} / \mathrm{ml} \mathrm{SHAM} \mathrm{and} \mathrm{with-}$ out the AOX inhibitor. Each concentration was tested in triplicate using B. oryzae isolate TG12Lb2, and percent germination of 100 spores was evaluated for each replicate. The experiment was replicated twice.

To determine if the AOX pathway was active in the 16 baseline isolates, spore germination was tested in in vitro assays with azoxystrobin $(5 \mu \mathrm{g} / \mathrm{ml})$ with and without SHAM $(100 \mu \mathrm{g} / \mathrm{ml})$ using the same methodology described above. The experiment was replicated twice.

Assessment of azoxystrobin sensitivity of the $B$. oryzae baseline isolates. Sixteen $B$. oryzae isolates collected in 2007 prior to the widespread application of azoxystrobin-based fungicides in wild rice paddies were used as a baseline population to determine sensitivity to azoxystrobin by calculating the $\mathrm{EC}_{50}$ value, the concentration that inhibits spore germination by $50 \%$. A spore suspension of 30 to $50 \mu \mathrm{l}$ at an approximate concentration of $1 \times 10^{5}$ conidia $/ \mathrm{ml}$ was used to inoculate $1.5 \%$ water agar amended with $100 \mu \mathrm{g} / \mathrm{ml}$ SHAM and azoxystrobin at 5, 2.5, 1.25, 0.625, 0.313, 0.156, 0.078 , and $0 \mu \mathrm{g} / \mathrm{ml}$. All concentrations were tested in triplicate. The plates were placed in a translucent plastic container in a room at $24^{\circ} \mathrm{C}\left( \pm 1^{\circ} \mathrm{C}\right)$. Percent germination of 100 spores in each replicate was determined 17 to $18 \mathrm{~h}$ after plating. At least two independent experiments were conducted for each of the 16 isolates to determine an average $\mathrm{EC}_{50}$ value.

The $\mathrm{EC}_{50}$ values for the baseline isolates were evaluated in two ways. Relative germination (RG) of each isolate was calculated from 
percent spore germination of each isolate with azoxystrobin in the medium divided by percent spore germination of the isolate without azoxystrobin multiplied by 100 (Rosenzweig et al. 2008; Vincelli and Dixon, 2002). The RG values were plotted against the $\log _{10}$ of azoxystrobin concentration and a linear regression was calculated in Excel. The $\mathrm{EC}_{50}$ value concentration for each individual isolate was calculated from the $\mathrm{RG}=50 \%$, and the corresponding $\log _{10}$ azoxystrobin value interpolated from the two closest concentrations and converted back to $\mu \mathrm{g} / \mathrm{ml}$. Additionally, $\mathrm{EC}_{50}$ values were estimated using the PROBIT option from the regression function in IBM SPSS Statistics software version 24 (IBM Corporation, Armonk, NY) that uses maximum likelihood for estimation of the linear regression to determine $\mathrm{EC}_{50}$. The input variables used were the response spore number (germination inhibition) by concentration for each isolate, total observed spores, and the corresponding azoxystrobin concentrations, which were converted to $\log _{10}$ by the software. Reproducibility of $\mathrm{EC}_{50}$ mean values for each baseline isolate was tested by calculating the absolute coefficient of variation (CV) for each experiment (Rosenzweig et al. 2008). The 95\% confidence intervals were calculated as CI $=$ Mean $\pm 1.96(\mathrm{SEM} / \mathrm{sqrt}(n))$, where SEM $=$ standard error of the mean and $n=$ the number of individuals tested.

Evaluation of 2008, 2015, and 2016 B. oryzae isolates for azoxystrobin sensitivity in vitro. $B$. oryzae isolates collected during 2008 (16 isolates), 2015 (78 isolates), and 2016 (77 isolates) were tested for germination on $1.5 \%$ water agar plates with $100 \mu \mathrm{g} / \mathrm{ml}$ SHAM and a discriminatory dose of $0.4 \mu \mathrm{g} / \mathrm{ml}$ azoxystrobin, the average $\mathrm{EC}_{50}$ value determined for the baseline isolates. All isolates were tested in triplicate by assessing percent germination of 100 spores in each replicate. Because tests were done on different days, the isolate TG12Lb2 was used in each test as a standard. Percent germination greater than $50 \%$ indicated that the isolate was a potential mutant with decreased sensitivity to azoxystrobin. The RG at $0.400 \mu \mathrm{g} / \mathrm{ml}$ azoxystrobin for 2007 baseline isolates were estimated from the regression curves for comparison with the rest of the populations. A frequency distribution of $\mathrm{RG}$ values in each population was constructed by placing the isolates into 10 arbitrary RG categories: 1 to $10 \%, 11$ to $20 \%, 21$ to $30 \%, 31$ to $40 \%, 41$ to $50 \%, 51$ to $60 \%, 61$ to $70 \%, 71$ to $80 \%, 81$ to $90 \%$, and 91 to $100 \%$. Normality of the distributions was tested using the Shapiro-Wilk test. A oneway analysis of variance (ANOVA) was used to compare the RG means of the populations at a concentration of $0.4 \mu \mathrm{g} / \mathrm{ml}$ azoxystrobin. Comparisons between population mean RG values were done using the Tukey-Kramer HSD (honestly significant difference) test. Equality of variances was assessed using the Levene tests. All the analyses were tested at a significance level of $\alpha=0.05$ and done using JMPPro 13.0 software.

Amplification and analysis of cytochrome $b$ cDNA and cytochrome $b$ gene DNA sequence for the positions affecting fungicide resistance. The $16 \mathrm{~B}$. oryzae baseline isolates and one isolate from 2008 (TG12Lb2) were grown from spores in $200 \mathrm{ml}$ potato dextrose broth in 500-ml flasks for 4 to 5 days with shaking at $140 \mathrm{rpm}$ at $23^{\circ} \mathrm{C}\left( \pm 2^{\circ} \mathrm{C}\right)$. The mycelium was collected in sterile cheesecloth, rinsed with sterile deionized water, blotted dry, frozen immediately in liquid nitrogen, and stored at $-20^{\circ} \mathrm{C}$ until used. Total RNA extraction was done using the RNeasy Plant Mini kit (Qiagen) according to the manufacturer's recommendations, and genomic DNA was removed with Ambion DNase I (Life Technologies, Carlsbad, CA). cDNA synthesis was carried out with the iScript cDNA synthesis kit (Bio-Rad Laboratories Inc., Hercules, CA).

Primers As_5F and Asint4d_r from Alternaria solani (Grasso et al. 2006) were used for the amplification of a segment of the cytochrome $b$ cDNA for each isolate and included the nucleotides of the amino acid positions 129, 137, and 143 where substitutions resulting in fungicide resistance or reduced sensitivity are known to occur. The 25- $\mu$ l PCR reaction consisted of 50-100 ng cDNA, $12.5 \mu \mathrm{l}$ of GoTaq Green Master Mix (Promega), and $10 \mu \mathrm{M}$ of each primer. The touchdown PCR conditions were: $95^{\circ} \mathrm{C}$ for $3 \mathrm{~min}$; 12 cycles of $94^{\circ} \mathrm{C}$ for $30 \mathrm{~s}, 60^{\circ} \mathrm{C}$ (minus $0.5^{\circ} \mathrm{C} /$ cycle) for $1 \mathrm{~min}, 72^{\circ} \mathrm{C}$ for $1 \mathrm{~min} ; 20$ cycles of $94^{\circ} \mathrm{C}$ for $30 \mathrm{~s}, 54^{\circ} \mathrm{C}$ for $1 \mathrm{~min}$, and $72^{\circ} \mathrm{C}$ for $1 \mathrm{~min}$; with an extension step of $72^{\circ} \mathrm{C}$ for $7 \mathrm{~min}$. PCR products were visualized in $1 \%$ agarose after staining with ethidium bromide using Image Lab software (version 5.1) in a Gel Doc EZ Imager (Bio-Rad Laboratories, Inc.) and purified using the QIAquick PCR purification kit (Qiagen). Classic Sanger sequencing of both strands was carried on at the University of Minnesota Genomics Center using $6.4 \mu \mathrm{M}$ of each primer.

Fungal DNA extractions were done using Gentra Puregene (Qiagen). DNA from B. oryzae isolate GU8-1 40_59 collected in 2008 was used in PCR reactions to amplify genomic DNA segments of intron 1 , exon 2 , and verify the presence of an intron after position G143 of exon 2 of the cytochrome $b$ gene. Primers were designed using the $A$. solani DNA sequence DQ209284 as template and included nucleotides 901 to 3,420 containing partial sequences of intron 1, complete sequences of exon 2, intron 2, and exon 3. Additional DNA segments between exon 2 part A and exon 2 part B of B. oryzae were amplified using primers designed from B. maydis (AC277191.1), and gaps were closed from B. oryzae GU8-1 40_59 amplified DNA sequences. The PCR reactions were done as specified above for amplification from cDNA. Primer sequences used in this study are listed in Supplementary Table S1.

cDNA and DNA sequences were uploaded, edited, manually corrected, and a consensus sequence was obtained in Sequencher software (version 4.01.1; Gene Codes Corp., Ann Arbor, MI). The software RNAweasel (http://megasun.bch.umontreal.ca/RNAweasel) was used to predict the intron type with default settings (Lang et al. 2007). This software uses the search engine ERPIN (Easy RNA Profile IdentificatioN; http://tagc.univ-mrs.fr/erpin) based on primary and secondary RNA structures but improved by visualization, editing, automatization of alignments, and enhanced sensitivity and reiterative search modes.

To assess if the differential RG among B. oryzae isolates in 2008, 2015, and 2016 was due to the presence of known mutations, DNA templates from a small representative set of those isolates were used in separate PCR reactions with primers TTA-TTC_F and TTCTTA_R to amplify the position 129 , and the primers $\bar{C}$ h_Int1-Int2F and Ch_Int1-Int2R for position 137, which also amplify position 143. Eleven isolates that had an RG of $\geq 80 \%$ and eight isolates with an RG of $\leq 40 \%$ were tested (Supplementary Table S2). The PCR conditions and sequencing were as described above. cDNA of five of those isolates (WR3d_56, WR40_59, PI8_142, RR8_L2_97, and PI25_151) representing low and high RG was produced from mycelium grown in potato dextrose broth with and without 0.4 $\mu \mathrm{g} / \mathrm{ml}$ azoxystrobin, and used to amplify the targeted area with primers As_5F and Asint4d_r. cDNA and DNA sequences were analyzed as above.

AOX gene expression. Expression of the AOX gene in the presence and absence of azoxystrobin was investigated by in vitro and in planta experiments. For the in vitro experiments, the isolate TG12Lb2 was grown in $150 \mathrm{ml}$ potato dextrose broth amended with $5 \mu \mathrm{g} / \mathrm{ml}$ azoxystrobin in a 500-ml flask with shaking at $140 \mathrm{rpm}$ at room temperature. A control culture without azoxystrobin but with acetone $(1 \% \mathrm{vol} / \mathrm{vol})$ was also grown. Mycelium was collected after 24 and $48 \mathrm{~h}$ of growth by filtering through sterile cheesecloth, rinsed two times with sterile deionized water, blotted on sterile filter paper, frozen in liquid nitrogen, and kept at $-80^{\circ} \mathrm{C}$ until used for RNA extraction.

The in planta experiments were done in a greenhouse using wild rice plants grown as reported previously (Castell-Miller et al. 2016). Plants were sprayed with $5 \mu \mathrm{g} / \mathrm{ml}$ azoxystrobin $24 \mathrm{~h}$ before inoculation. Control plants were sprayed with water. The inoculum consisted of 8,000 to 10,000 conidia/ml in sterile deionized water plus $0.01 \% \mathrm{vol} / \mathrm{vol}$ Tween 20 applied with a plastic bottle sprayer to a final volume of about $10 \mathrm{ml} /$ plant. Leaf tissue was harvested at $24 \mathrm{~h}$ and $48 \mathrm{~h}$ after inoculation and frozen immediately in liquid nitrogen and stored at $-80^{\circ} \mathrm{C}$ until used for RNA extraction. Two separate experiments were conducted, each with at least two biological replicates.

Total RNA extraction, DNA removal, and cDNA synthesis was done as described above. Primers Cm_AOX_Set1F and $\mathrm{Cm}_{-}$ AOX_Set1R were designed from the AOX gene of isolate TG12Lb 2 
(Cm_1909; available in the Whole Genome Shotgun project deposited at GenBank under the accession LNFW00000000) using the SciTools software at IDT (http://www.idtdna.com/scitools/Applications/ RealTimePCR). qRT-PCR assays were conducted in an Applied Biosystems 7500/7500 Fast Real-Time PCR system (Applied Biosystems, Foster City, CA) as described previously (Castell-Miller et al. 2016). The delta-delta $\mathrm{Ct}$ method was used to determine relative expression of the AOX gene and was calculated by the Applied Biosystems software. Expression data were normalized against an endogenous control (glyceraldehyde-3-phosphate dehydrogenase). Two independent experiments were conducted for each in vitro and in planta assay. Within each experiment, two biological replications with at least three technical replicates were analyzed. Data are presented as the $\log _{2}$ of relative gene expression (foldchange). Expression values in the reference sample were set to $0\left(\log _{2}=1\right)$. Significance of differential gene expression between the control without azoxystrobin and each of the time-point treatments with azoxystrobin was tested using one tailed $t$ tests with equal variances with the significance threshold set at 0.05 under the null hypothesis that both means belong to the same population.

\section{Results}

Evaluation of SHAM potentiation on azoxystrobin sensitivity and determination of the SHAM dose for AOX inhibition in in vitro azoxystrobin assays. There was no statistically significant difference in spore germination with increasing SHAM concentrations $(0,50,100$, and $150 \mu \mathrm{g} / \mathrm{ml})$ for any of the four isolates tested (Supplementary Table S3). Thus, $100 \mu \mathrm{g} / \mathrm{ml} \mathrm{SHAM}$ was used in all other experiments to block the AOX pathway when testing the efficacy of azoxystrobin in inhibiting spore germination.

Spore germination of $B$. oryzae isolate TG12Lb2 was not inhibited by increasing azoxystrobin concentrations in the absence of SHAM, even though some reduction in hyphal length and branching was observed at higher concentrations. However, inhibition of spore germination occurred in an azoxystrobin dose-dependent manner when $100 \mu \mathrm{g} / \mathrm{ml} \mathrm{SHAM} \mathrm{was} \mathrm{added} \mathrm{to} \mathrm{the} \mathrm{medium,} \mathrm{suggesting} \mathrm{that} \mathrm{the}$ AOX pathway is active and potentiated azoxystrobin sensitivity in in vitro assays (Fig. 1). Germination of a set of 16 baseline isolates tested at $5 \mu \mathrm{g} / \mathrm{ml}$ azoxystrobin had germination rates of at least $87 \%$ in the absence of SHAM (Supplementary Table S4), while none germinated when SHAM was added at $100 \mu \mathrm{g} / \mathrm{ml}$.

$\mathbf{E C}_{50}$ values of the B. oryzae baseline population. Using a linear regression analysis, the average $\mathrm{EC}_{50}$ value of the baseline $B$. oryzae collection was estimated to be $0.427 \mu \mathrm{g} / \mathrm{ml}$ azoxystrobin $(\mathrm{SEM}=$ 0.029 ), ranging from $0.169 \mu \mathrm{g} / \mathrm{ml}$ for isolate BPW16 to $0.620 \mu \mathrm{g} / \mathrm{ml}$ for isolate SL42 (Table 1) with the overall collection 95\% CI ranging from 0.386 to $0.467 \mu \mathrm{g} / \mathrm{ml}$. The mean absolute $\mathrm{CV}$ over the collection was 0.074. Similar results were obtained with a PROBIT regression analysis, with an average $\mathrm{EC}_{50}$ of $0.394 \mu \mathrm{g} / \mathrm{ml}$ azoxystrobin $(\mathrm{SEM}=0.029)$ and values ranging from 0.176 to $0.611 \mu \mathrm{g} / \mathrm{ml}$ for the same isolates, an absolute CV of 0.078 , and $95 \%$ CI varying from 0.297 to $0.546 \mu \mathrm{g} / \mathrm{ml}$ (Table 1 ). There was roughly a 3.5 -fold difference between the smallest and the largest $\mathrm{EC}_{50}$ values corresponding to isolates BPW16 and SL42. The $\mathrm{EC}_{50}$ value of $0.4 \mu \mathrm{g} / \mathrm{ml}$ was used as a "discriminatory dose" for assessing isolates collected in 2008, 2015, and 2016 and identifying putative resistant and/or less sensitive isolates.

Evaluation of isolates collected in 2008, 2015, and 2016 for azoxystrobin sensitivity. The mean spore RG of the 16 isolates collected in 2008 using $0.4 \mu \mathrm{g} / \mathrm{ml}$ azoxystrobin was 59\% (SEM = $2.42 \%)$ with a minimum value of $24 \%(\mathrm{SEM}=0.58 \%)$ for isolate WR3d_56 and maximum value of $88 \%($ SEM $=2.81 \%)$ for isolate GU8-1 40_59, collected at Baudette and Gully, MN, respectively. For the 78 isolates collected in 2015, the average spore RG was $66 \%(\mathrm{SEM}=2.97 \%)$ with a minimum of $29 \%(\mathrm{SEM}=5.79 \%)$ for isolate RS7_L2_180 and a maximum RG of $89 \%($ SEM $=3.21 \%$ ) for isolate RS27a_206, both from Clearbrook. The average RG of spores of the 77 isolates from 2016 was $55 \%($ SEM $=3.06)$ with a minimum of $12 \%(\mathrm{SEM}=2.85 \%)$ for isolate RR5_76 from Waskish

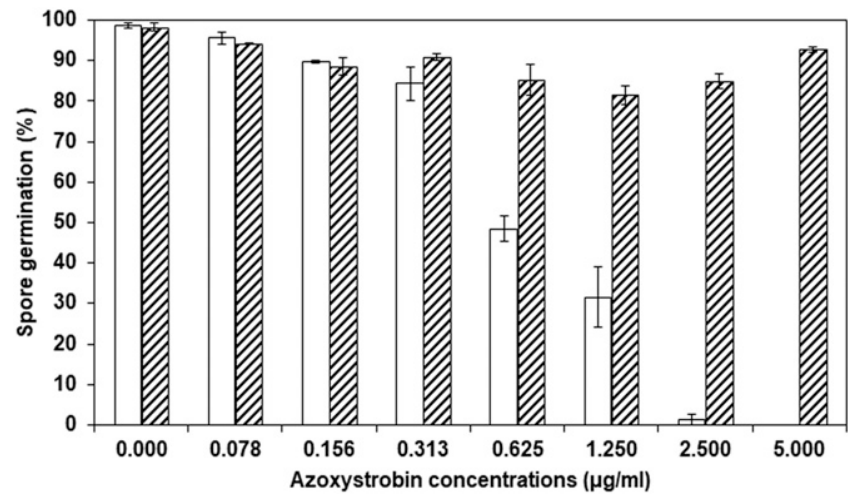

Fig. 1. Bipolaris oryzae spore germination in water agar with different concentrations of azoxystrobin amended with and without SHAM. Percent spore germination with $100 \mu \mathrm{g} / \mathrm{ml}$ SHAM (white columns) and $0 \mu \mathrm{g} / \mathrm{ml}$ SHAM (dashed columns). Bars indicate standard error of the mean.

Table 1. Determination of azoxystrobin $\mathrm{EC}_{50}$ values for the baseline Bipolaris oryzae population collected in 2007 by linear and PROBIT regression methods

\begin{tabular}{|c|c|c|c|c|c|c|}
\hline \multirow[b]{2}{*}{ Isolate } & \multicolumn{3}{|c|}{ Linear regression } & \multicolumn{3}{|c|}{ PROBIT regression } \\
\hline & Mean $(\text { SEM) })^{\mathbf{a}}$ & $\mathbf{C V}^{\mathbf{b}}$ & $95 \% \mathrm{CI}^{\mathrm{c}}$ & Mean $\left(\right.$ SEM) ${ }^{\mathbf{a}}$ & $\mathbf{C V}^{\mathbf{b}}$ & $95 \% \mathrm{CI}^{\mathrm{c}}$ \\
\hline BPW7 & $0.380(0.067)$ & 0.175 & $0.287-0.472$ & $0.343(0.062)$ & 0.181 & $0.269-0.433$ \\
\hline BPW8 & $0.351(0.038)$ & 0.108 & $0.298-0.404$ & $0.310(0.031)$ & 0.100 & $0.236-0.401$ \\
\hline BPW15 & $0.359(0.019)$ & 0.052 & $0.333-0.385$ & $0.317(0.034)$ & 0.106 & $0.252-0.396$ \\
\hline BPW16 & $0.169(0.037)$ & 0.217 & $0.118-0.219$ & $0.176(0.024)$ & 0.134 & $0.133-0.222$ \\
\hline BPW19 & $0.315(0.037)$ & 0.117 & $0.264-0.366$ & $0.270(0.029)$ & 0.107 & $0.223-0.327$ \\
\hline BPW21 & $0.396(0.001)$ & 0.001 & $0.395-0.396$ & $0.349(0.003)$ & 0.008 & $0.259-0.466$ \\
\hline BPW26 & $0.589(0.015)$ & 0.025 & $0.568-0.610$ & $0.569(0.039)$ & 0.068 & $0.435-0.773$ \\
\hline BPW38 & $0.513(0.044)$ & 0.085 & $0.452-0.573$ & $0.500(0.054)$ & 0.108 & $0.387-0.648$ \\
\hline BPW45 & $0.319(0.006)$ & 0.017 & $0.311-0.326$ & $0.287(0.005)$ & 0.017 & $0.230-0.353$ \\
\hline BPW47 & $0.379(0.039)$ & 0.102 & $0.325-0.432$ & $0.348(0.029)$ & 0.084 & $0.255-0.467$ \\
\hline BPW51 & $0.522(0.044)$ & 0.083 & $0.461-0.582$ & $0.493(0.045)$ & 0.091 & $0.350-0.700$ \\
\hline ML22 & $0.595(0.030)$ & 0.050 & $0.553-0.637$ & $0.574(0.044)$ & 0.077 & $0.445-0.745$ \\
\hline ML28 & $0.219(0.024)$ & 0.110 & $0.186-0.252$ & $0.215(0.015)$ & 0.069 & $0.142-0.301$ \\
\hline ML39 & $0.603(0.050)$ & 0.082 & $0.534-0.671$ & $0.574(0.058)$ & 0.101 & $0.368-0.931$ \\
\hline ML42 & $0.505(0.005)$ & 0.009 & $0.498-0.511$ & $0.475(0.001)$ & 0.002 & $0.351-0.638$ \\
\hline SL42 & $0.620(0.016)$ & 0.025 & $0.598-0.641$ & $0.611(0.021)$ & 0.034 & $0.411-0.927$ \\
\hline Mean & $0.427(0.029)$ & 0.074 & $0.386-0.467$ & $0.394(0.029)$ & 0.078 & $0.297-0.546$ \\
\hline
\end{tabular}

a SEM: standard error of the mean.

${ }^{\mathrm{b}} \mathrm{CV}$ : absolute coefficient of variation.

${ }^{\mathrm{c}} \mathrm{CI}$ : confidence interval. 
and a maximum $\mathrm{RG}$ of $87 \%(\mathrm{SEM}=2.66 \%)$ for isolate TG29 0 from Aitkin. The RG of the control isolate TG12Lb2 was 78\% (SEM = 2.00). The absolute $\mathrm{CV}$ of this isolate was 0.026 in 21 tests, indicating robustness in replication of the assays. A total of 13 (2008), 73 (2015), and 60 (2016) isolates had an RG $\geq 50 \%$, and three (2008), 13 (2015), and eight (2016) had an RG of $80 \%$ or above. The RG of the 2007 baseline population was $54 \%(\mathrm{SEM}=4.22)$ with a minimum value of $20 \%(\mathrm{SEM}=2.00 \%)$ for isolate BPW16 from Palisade, $\mathrm{MN}$ and maximum value of $75.5 \%$ ( $\mathrm{SEM}=8.00 \%)$ for SL42 collected at Shovel Lake, MN. This mean RG value is within the variation expected from the $\mathrm{EC}_{50}$ values determined for this baseline population.

The frequency distribution of spore RG indicated that isolates from 2015 and 2016 were skewed toward higher germination rates (Fig. 2), although normally distributed $(P=0.102$ and $P=0.741$, respectively), as were RG rates for the $2007(P=0.268)$ and $2008(P=$ 0.141 ) populations. Thus, a parametric approach was used to compare the mean RGs for the four collections. The ANOVA test showed that there were statistically significant differences $(P=0.006)$ among the RG means of the four collections. Comparisons among means of the collections indicated that only the mean RG of 2015 and of 2016 isolates were statistically different when tested at an azoxystrobin concentration of $0.4 \mu \mathrm{g} / \mathrm{ml}$.

Analysis of the cytochrome $b$ sequence involved in resistance to azoxystrobin. Fragments of at least $400 \mathrm{bp}$ of cytochrome $b$ were amplified from cDNA of the 16 baseline isolates and isolate TG12Lb2 that included the target area known for mutations leading to strobilurin resistance. All sequences were identical and have been deposited in GenBank (MK300825 to MK300841). The three "hot spots" for mutations to azoxystrobin resistance at positions F129, G137, and G143 were the wild type. The B. oryzae cDNA consensus sequence matched the cytochrome $b$ subunit of the $b c$ complex (COG1290) and had 97\% sequence identity to the cDNA of cytochrome $b$ of Alternaria solani (DQ290285) (Supplementary Fig. $\mathrm{S} 1)$. The same cytochrome $b$ cDNA fragment was sequenced from a set of five $B$. oryzae isolates collected in 2008, 2015, and 2016 grown with and without azoxystrobin, and all had the wild type alleles for the three positions. These isolates had a slightly higher $(\geq 80 \%)$ or lower $(\leq 40 \%)$ RG when tested with the discriminatory dose of $0.4 \mu \mathrm{g} / \mathrm{ml}$ azoxystrobin. A consensus sequence by isolate was constructed, and the five sequences were deposited in GenBank under accessions MK300842 to MK300846. Additionally, short genomic DNA sequences of the cytochrome $b$ that included positions F129, G137, and G143 were also amplified with specific primers from 19 isolates representative of high and low RG values. All isolates had F129, G137, and G143 sequences, indicating that the wild type was the predominant, if not unique allele.

Genomic DNA of B. oryzae isolate GU8-1 40_59 $(\mathrm{RG}=88 \%)$ was used to amplify segments of intron 1, the complete sequence of exon 2 , and intron 2 of the cytochrome $b$ gene. Primers were designed spanning nucleotides 901 to 3,420 in the A. solani DNA sequence DQ209284. Although intron 1 from $A$. solani and B. oryzae share some conserved sequences, they are not identical in composition. A segment of intron 1 in $B$. oryzae amplified with the primer pair (AsInt1D1) corresponded to $220 \mathrm{bp}$ (nucleotides 933 to 1,152) out of 1,139 bp of intron 1 in $A$. solani with $99 \%$ identity, and terminating at about 40 nucleotides from the start of exon 2.

The $B$. oryzae cDNA consensus sequence also matched segments of $B$. maydis DNA sequence (AC277191.1). That is, B. oryzae cDNA nucleotides 1 to 52 (partial exon 1), 53 to 66 (first part of exon 2), 67 to 102 (second part of exon 2), 112 to 163 (exon 4), and 164 to 449 (exon 5) matched the B. maydis sequence at positions 9,869 to 9,920 $(\mathrm{e}$-value $=9 \mathrm{e}-23), 12,033$ to $12,048(\mathrm{e}-\mathrm{value}=0.004), 13,367$ to $13,402$ (e-value $=7 \mathrm{e}-14), 19,810$ to $19,861(\mathrm{e}-\mathrm{value}=2 \mathrm{e}-23)$, and 21,141 to 21,426 (e-value $=7 \mathrm{e}-153$ ), respectively. Exon 3 of $B$. oryzae (nucleotides 103 to 110 ), only 9 bp long, was found by visual inspection of the B. maydis sequence (positions 18,044 to 18,052 ). A schematic representation of the cytochrome $b$ gene in Bipolaris spp. is shown in Figure 3A.
A

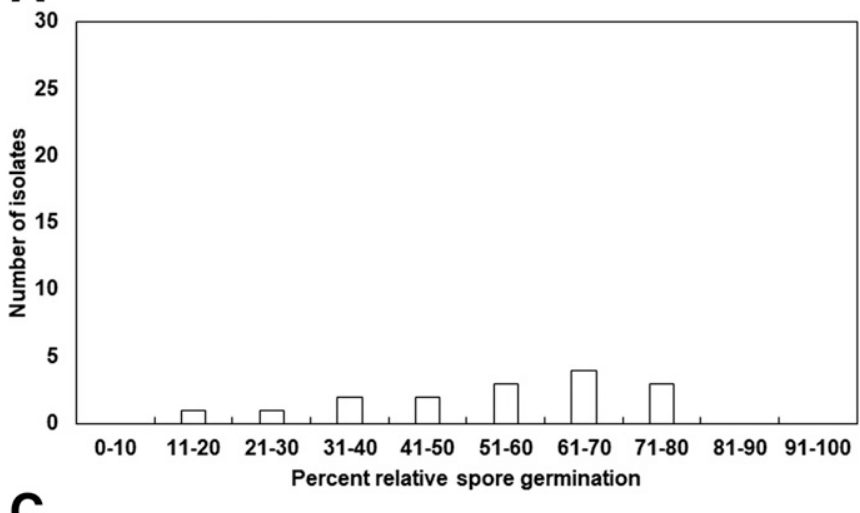

C

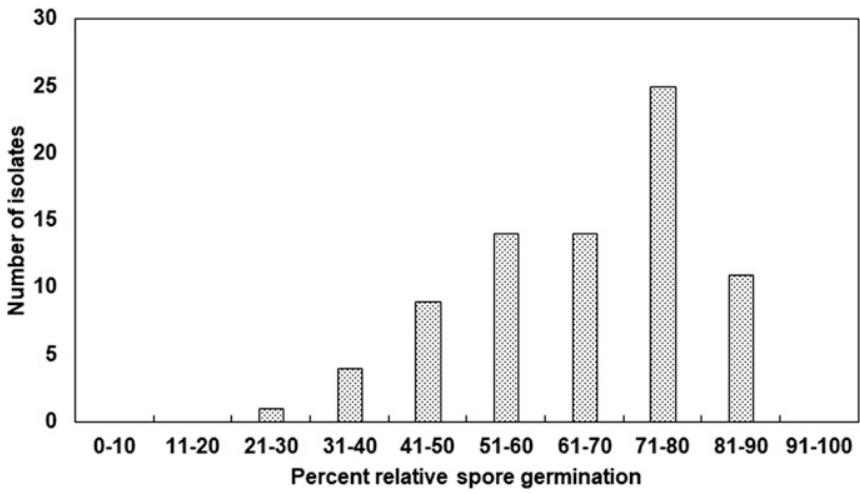

B

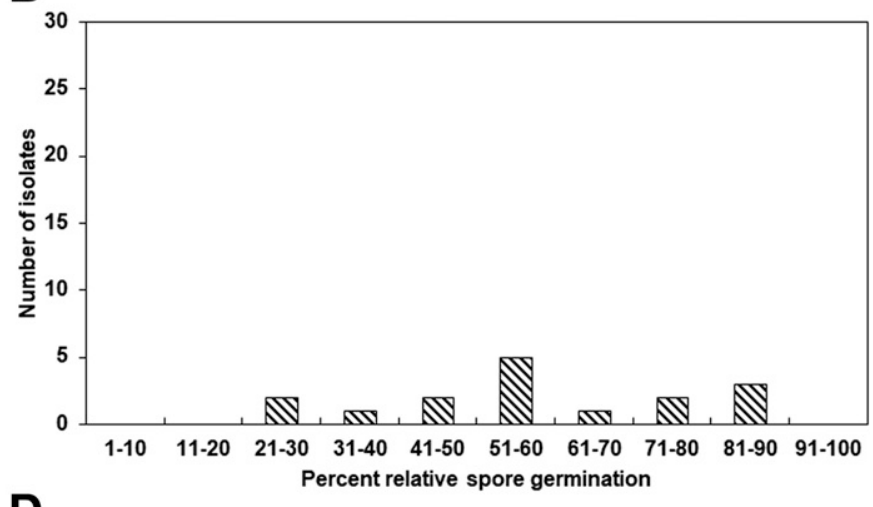

D

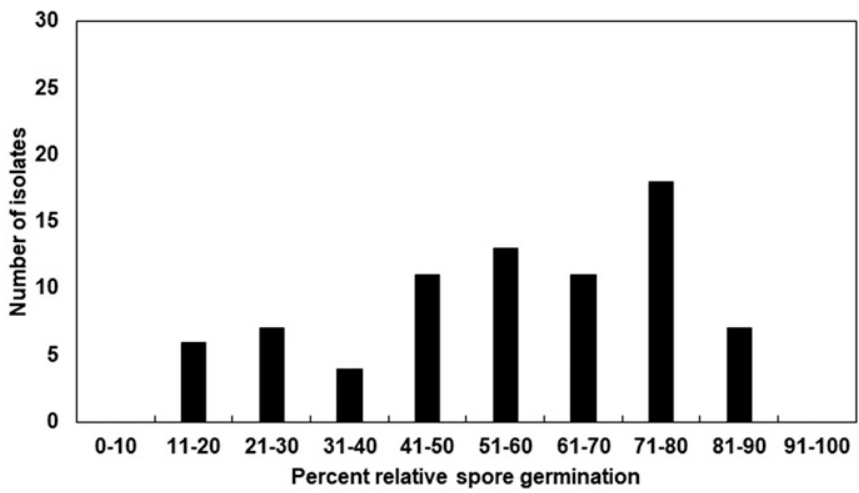

Fig. 2. Frequency distribution histograms of Bipolaris oryzae relative germination at the $\mathrm{EC}_{50}$ azoxystrobin rate of $0.400 \mu \mathrm{g} / \mathrm{ml}$ in the presence of SHAM at $100 \mu \mathrm{g} / \mathrm{ml}$. A, 2007 population, B, 2008 population, C, 2015 population, D, 2016 population. 
Genomic DNA of exon 2 and intron 2 of B. oryzae was amplified using a combination of primers designed from A. solani (DQ209284) and $B$. maydis (AC277191.1) as well as from amplified DNA sequences of $B$. oryzae. In contrast to the $A$. solani cytochrome $b$ gene, exon 2 in $B$. oryzae and $B$. maydis was found to be split into two smaller exons, exon $2 \mathrm{~A}$ and exon $2 \mathrm{~B}$ of 17 and $34 \mathrm{bp}$, respectively, separated by a $1,520 \mathrm{bp}$ intron, hereafter called intron $2 \mathrm{~A}$. A third intron, henceforth called intron $2 \mathrm{~B}$, was identified immediately after the codon for G143. This intron of 4,546 bp has the canonical signatures corresponding to Group I introns: an exonic "T" located upstream of the 5 ' end of the splice site and a " $G$ " immediately before the intron $3^{\prime}$ splice site, a putative internal guide sequence for exon/intron splicing (T(U)GAGGT(U)) at the $3^{\prime}$ end of the exon 2B splice site and another set (GCCT(U)CA) near the $5^{\prime}$ splice site of intron $2 \mathrm{~B}$. A schematic representation of this segment in B. oryzae is shown in Figure 3B.

Introns $2 \mathrm{~A}$ and $2 \mathrm{~B}$ were identified as belonging to intron Group I subgroup " $\mathrm{D}$ " within the nine predicted models available using the RNAweasel bioinformatics pipeline. Core elements that characterize the Group I introns were identified for intron $2 \mathrm{~A}(\mathrm{e}-\mathrm{value}=7.7 \mathrm{e}-40)$ and intron $2 \mathrm{~B}$ (e-value $=5.3 \mathrm{e}-38)$ (Fig. 3B). In addition, intron $2 \mathrm{~A}$ contains a catalytic GIY-YIG conserved domain $(\operatorname{cd} 10445 ;$ e-value $=$ 2.7 e-20) of a putative intron-encoded endonuclease with a bl1like region containing a C-terminus with a possible DNA binding site (e-value $=5.0 \mathrm{e}-04)$. The bll region could be associated with intron homing and thus promote the mobility of introns. Intron 2B contained conserved domains for a putative $\mathrm{N}$-acetyltransferase in the RimJ/ RimL family (COG1670) involved in translation, ribosomal structure and biogenesis, posttranslational modification, and protein turnover.
AOX gene expression in vitro and in planta. The AOX primers amplified a PCR product of $167 \mathrm{bp}$ that matched the AOX $\left(\mathrm{Cm}_{-}\right.$ 1909) gene sequence. Averaged over two independent in vitro experiments, AOX expression in the presence of azoxystrobin was upregulated 7.2-fold (SEM $=0.130)$ at $24 \mathrm{~h}$ after inoculation and statistical significantly different $(P<0.001)$ compared with the control without azoxystrobin. Similarly, at $48 \mathrm{~h}$ after inoculation, the AOX expression was 6.7-fold higher than the control $(\mathrm{SEM}=0.244)$ and significantly different $(P<0.001)$.

AOX expression was detected at both time points in both experiments when the fungus was inoculated onto wild rice leaves previously treated with azoxystrobin. However, from control leaves treated with water, AOX gene expression was detected in only one of the two experiments at only $48 \mathrm{~h}$ after inoculation. In this case, relative AOX expression was nearly fourfold higher in the azoxystrobin treated leaves compared with expression in the control (data not shown).

\section{Discussion}

Fungicides have played a crucial role in controlling plant diseases and reducing crop losses. Strobilurin fungicides have been widely used due to their benefits of effectively suppressing a wide range of fungi and promoting plant physiological changes that enhance yields (Blandino et al. 2012), but because they have a single molecular target, resistance has developed in a number of fungal pathogens. Azoxystrobin-based fungicides have been used on wild rice since 2006, mainly to control foliar diseases within an IDM system. However, from 2013 to 2015, substantial grain yield losses of wild rice occurred, primarily due to epidemics of FBS caused by $B$. oryzae. Our goal was to determine the sensitivity of $B$. oryzae populations

A

Intron 1 Intron $2 \mathrm{~A}$ $(1,320 \mathrm{bp})$
Intron 2B

$(4,546 \mathrm{bp})$
Intron 3

Intron 4

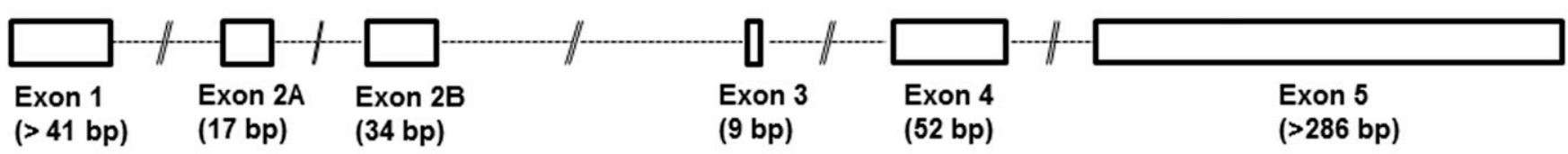

B

Exon2A

Intron 2A

AGACAGCTITCCTGGGTTA ccaaca...1,101 bp ...gGCGATATTAGTGAATACGGTTAAAGAAGCTTAATAAACTTTAAGA

Intron $2 \mathrm{~A}$ cont

CCGTCGGCCATATAAAGGGTCGCTACAGACTGGGTCACTAATGGGTGGCTGAAATGCTGCTTAATGTACAGGCGA...

Intron 2A cont. Exon 2B

Intron 2B cont.

86 bp...tttgta TGTTCTTCCTTATGGGCAATGTCACTATGAGG aaaattttGCCTCA...4,193 bp .... AGCAATGCTTGTGA

Intron 2B cont.

AAACGGTCAAATATATTTGTTTAGTATAAAGACCGTCGGTATAATAAAATATCGCTACAGACTGGTTCACAGGTGGGTA

Intron 2B cont.

Exon 3

GCTGAAATGCTGCTTAATGTACAGTCGG...211 bp....gattg GCTACAGTT

Fig. 3. Cytochrome $b$ structure of Bipolaris oryzae. A, Schematic representation of the positions of exons 1 to 5 based on the complete gene sequence from Bipolaris maydis FNFP221-N11 (AC277191.1), and the neighboring nucleotides for exon and intron boundaries described for Alternaria solani (DQ209284) in Grasso et al. (2006). Drawing not to scale. B, B. oryzae DNA sequence of exon 2A with position F129 underlined, exon 2B with positions G137 and G143 underlined and exon 3 (boxed red uppercase letters). Schematic representation of intron $2 \mathrm{~A}(1,520 \mathrm{bp})$ and intron $2 \mathrm{~B}(4,546 \mathrm{bp})$ with first and last six to nine nucleotides of each intron (lowercase black letters). Putative core elements of Group I introns are shown in uppercase and underlined black letters. Numbers before and after the core elements represent bases not shown. Canonical

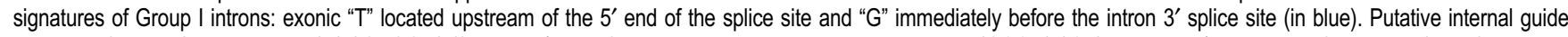
sequence for exon/intron splicing (T(U)GAGGT(U)) at the $3^{\prime}$ end of the exon $2 \mathrm{~B}$ splice site and another set (GCCT(U)CA) near the $5^{\prime}$ splice site of intron $2 \mathrm{~B}$ (italics). 
to azoxystrobin over the time in which the chemical has been used for fungal disease control in wild rice.

The baseline $\mathrm{EC}_{50}$ is used as a reference value to determine if changes in sensitivity of field fungal populations occur over time under chemical pressure (Russell 2003). An $\mathrm{EC}_{50}$ of $0.4 \mu \mathrm{g} / \mathrm{ml}$ azoxystrobin was selected as a discriminatory dose after testing $16 \mathrm{~B}$. oryzae baseline isolates collected in 2007 from locations without a previous known history of exposure to azoxystrobin. The precision of assays was high (absolute $\mathrm{CV}<0.08$ ) and similar to that found in in vitro experiments of baseline isolates of $A$. solani (Rosenzweig et al. 2008). The range of $\mathrm{EC}_{50}$ values of $B$. oryzae baseline isolates was similar to those found in Monilinia fructicola baseline isolates (Luo et al. 2010). An azoxystrobin discriminatory dose was used to characterize $171 \mathrm{~B}$. oryzae isolates from fields exposed to azoxystrobin during 3 years $(2008,2015$, and 2016) of FBS epidemics. No resistant isolates were identified, although the frequency distributions of the spore RG values for the 2015 and 2016 populations were slightly shifted toward higher percent germination at the discriminatory dose compared with that of the 2008 population. However, the frequency distribution RGs of the baseline population were also slightly skewed toward higher values as those in 2015 and 2016, suggesting that the shift in the those two populations is unlikely due to an increase in tolerance to azoxystrobin. Additionally, the average and range for RG of 2007 and 2008 isolates were similar and not statistically significantly different from those of isolates from 2015 and 2016, even though the mean RG of 2008 isolates was smaller than that of 2016 isolates. This was likely due to a larger variability and lower number of available isolates tested within the 2008 group. Within the three azoxystrobin-exposed populations, 11 isolates that had a spore RG of $80 \%$ or higher, and eight with spore RG of $40 \%$ or lower, were selected for DNA sequencing of the areas of the cytochrome $b$ gene known to be involved in resistance to azoxystrobin. All isolates had the wild type gene sequence at the G143, G137, and F129 positions, as did the cDNA of a subset of five of those isolates grown with and without azoxystrobin, the cDNA of isolate TG12bL2 collected in 2008, and cDNA of the 2007 baseline collection. Thus, the differences in spore RG could not be attributed to known mutations in cytochrome $b$.

Comparisons of genomic and cDNA sequences identified an intron in the B. oryzae cytochrome $b$ gene after the G143 codon, which could preclude the fungus from developing qualitative resistance to azoxystrobin. Related Bipolaris and Cochliobolus species have been found to be at a low risk for developing resistance to strobilurin fungicides due to the presence of an intron immediately after position encoding G143 (Sierotzki 2015; Stammler 2012). The B. oryzae intron 2B was identified as a Group I intron similar to those found in A. solani, as well as rust species (Grasso et al. 2006) and Monilinia fructicola (Luo et al. 2010; Pereira et al. 2017) that have not developed resistance to azoxystrobin. A nucleotide change at the codon of the exon/intron border would negatively affect pre-mRNA splicing and consequently cytochrome $b$ function (Grasso et al. 2006; Vallières et al. 2011).

Group I introns have conserved secondary RNA structure and are commonly found in nuclear rRNA-encoding and fungal mitochondrial genes (Lang et al. 2007), and some have self-splicing mechanisms. Fungal mitochondrial genomes have been shown to lose and gain introns through evolution (Yin et al. 2012), and in some cases these are not favorable events. For example, acquisition of an intron after position 143 in some isolates of Botryotinia fuckeliana could have precluded the development of QoI fungicide resistance compared with intron-less isolates with the G143A mutation that are highly resistant (Yin et al. 2012). Interestingly, in S. cerevisiae, which has an intron after the G143 codon, a G143A mutation at the splice site that prevents intron excision could be compensated for by several mechanisms that bypass the defect and restore respiratory growth. It was suggested that similar bypass mechanisms could develop in plant-pathogenic fungi with long exposure to QoI inhibitors (Vallières et al. 2011).

$P$. teres and A. solani with an intron after position G143 have developed the mutation F129L that confers reduced sensitivity to QoI fungicides (Leiminger et al. 2013; Pasche et al. 2004), but B. oryzae isolates had the wild type sequences at F129 and G137. Both B. oryzae and $B$. maydis have an intron interrupting exon 2 of the cytochrome $b$ gene that is not found in A. solani. This group I intron encodes a putative homing endonuclease, a self-splicing enzyme that makes site-specific double-strand breaks in the target DNA and could promote the mobility of the intron and insertion into intron-less genes (Belfort and Roberts 1997). Intron Group I hosting homing endonucleases are regularly found in mitochondrial fungal genomes (Lang et al. 2007) and may encode conserved LAGLIDADG or GIY-YIG domains that may be involved in intron homing. Intron 2A of B. maydis and $B$. oryzae have GIY-YIG domains. Other plant-pathogenic fungi with this type of intron structure are B. fuckeliana, Podospora anserine, and Monilia yunnanensis with conserved GIY-YIG domains in the second Group I intron (Yin et al. 2012) and Stemphylium lycopersici with four Group I introns with GIY-YIG domains (Franco et al. 2017).

In in vitro assays, spores of $B$. oryzae isolates germinated at a wide range of azoxystrobin concentrations $(0.078$ to $5 \mu \mathrm{g} / \mathrm{ml})$ in the absence of the AOX pathway inhibitor SHAM, although all the isolates tested exhibited distortions in hyphal morphology and reduced branching compared with their growth without the fungicide. Similarly, a few baseline wild type isolates of Magnaporthe grisea had spore germination rates varying from 40 to $80 \%$ when tested with $10 \mu \mathrm{g} / \mathrm{ml}$ azoxystrobin without SHAM (Vincelli and Dixon 2002), indicating a natural genetic variation in tolerance. Inhibition of $B$. oryzae spore germination occurred in an azoxystrobin dose-dependent manner when $100 \mu \mathrm{g} / \mathrm{ml}$ SHAM was added, suggesting that the AOX pathway is active and effective in in vitro assays.

AOX gene expression was upregulated in B. oryzae after exposure to azoxystrobin in liquid growth medium. A similar response was reported in other fungi (Steinfeld et al. 2001; Xu et al. 2013; Yukioka et al. 1998). Our data also indicated AOX gene expression after the fungus was inoculated onto wild rice plants following azoxystrobin treatments. However, the AOX pathway is a less effective mechanism to generate ATP in comparison with the main route of the respiratory chain through cytochrome $b c l$ (Joseph-Horne et al. 2001; Wood and Hollomon 2003). Thus, the effectiveness of this pathway in fungal survival, especially during spore germination when challenged with azoxystrobin in the field is still unknown, and would need to be tested in future experiments.

This research investigated the sensitivity of B. oryzae to azoxystrobin after major FBS disease epidemics in cultivated wild rice. We found that there is variation in sensitivity in all the populations analyzed but the higher rate of spore germination at the discriminatory dose is not associated with mutations known to confer increased resistance. Epidemics were most likely the result of a buildup of inoculum, conducive environmental conditions, and late application of fungicides rather than fungicide resistance. However, continued monitoring of fungal populations is warranted due to possible development of DNA mutations or other mechanisms that can lead to reduced sensitivity. Additionally, continued IDM systems that include a low number of timely fungicide applications will reduce the potential risk of fungicide resistance. Development of disease resistant varieties will diminish potential yield losses and substantially reduce or eliminate the use of pesticide in wild rice production.

\section{Acknowledgments}

We thank the Minnesota Cultivated Wild Rice Council and growers for their support of the research. We thank Syngenta Crop Protection for providing azoxystrobin and E. Tedford for technical assistance. Nathan Paul provided excellent technical assistance with the Bipolaris oryzae collections.

\section{Literature Cited}

Ahmadpour, A., Castell-Miller, C. V., Javan-Nikkhah, M., Naghavi, M. R., Padasht Dehkaei, F., Leng, Y., Puri, K., and Zhong, S. 2017. Population structure, genetic diversity, and sexual state of the rice brown spot pathogen Bipolaris oryzae from three Asian countries. Plant Pathol. 67:181-192.

Avila-Adame, C., and Köller, W. 2002. Disruption of the alternative oxidase gene in Magnaporthe grisea and its impact on host infection. Mol. Plant-Microbe Interact. 15:493-500. 
Bartlett, D. W., Clough, J. M., Godwin, J. R., Hall, A. A., Hamer, M., and ParrDobrzanski, B. 2002. The strobilurin fungicides. Pest Manag. Sci. 58:649-662.

Belfort, M., and Roberts, R. J. 1997. Homing endonucleases: Keeping the house in order. Nucleic Acids Res. 25:3379-3388.

Blandino, M., Galeazzi, M., Savoia, W., and Reyneri, A. 2012. Timing of azoxystrobin + propiconazole application on maize to control northern corn leaf blight and maximize grain yield. Field Crops Res. 139:20-29.

Brantner, J. R. 1995. Survival, inoculum sources, and propiconazole sensitivity of Bipolaris species causing fungal brown spot of wild rice and host sensitivity to ophiobolin. M.S. Thesis. University of Minnesota, St. Paul.

Castell-Miller, C. V., Gutierrez-Gonzalez, J. J., Tu, Z. J., Bushley, K. E., Hainaut, M., Henrissat, B., and Samac, D. A. 2016. Genome assembly of the fungus Cochliobolus miyabeanus, and transcriptome analysis during early stages of infection on American wildrice (Zizania palustris L.). PLoS One 11:e0154122.

Castell-Miller, C. V., and Samac, D. A. 2012. Population genetic structure, gene flow and recombination of Cochliobolus miyabeanus on cultivated wild rice (Zizania palustris). Plant Pathol. 61:903-914.

Fernández-Ortuño, D., Torés, D. A., De Vicente, A., and Pérez-García, A. 2010. The QoI fungicides, the rise and fall of a successful class of agricultural fungicides. Pages 203-220 in: Fungicides. O. Carisse, ed. I. Publications. Croatia.

Franco, M. E. E., López, S. M. Y., Medina, R., Lucentini, C. G., Troncozo, M. I., Pastorino, G. N., Saparrat, M. C. N., and Balatti, P. A. 2017. The mitochondrial genome of the plant-pathogenic fungus Stemphylium lycopersici uncovers a dynamic structure due to repetitive and mobile elements. PLoS One 12:e0185545.

Gisi, U., Sierotzki, H., Cook, A., and McCaffery, A. 2002. Mechanisms influencing the evolution of resistance to Qo inhibitor fungicides. Pest Manag. Sci. 58:859-867.

Grasso, V., Palermo, S., Sierotzki, H., Garibaldi, A., and Gisi, U. 2006. Cytochrome $b$ gene structure and consequences for resistance to Qo inhibitor fungicides in plant pathogens. Pest Manag. Sci. 62:465-472.

Hollomon, D. W. 2015. Fungicide resistance: 40 years on and still a major problem. Pages 3-11 in: Fungicide Resistance in Plant Pathogens. H. Ishii and D. W. Hollomon, eds. Springer, New York.

Johnson, D. R., and Percich, J. A. 1992. Wild rice domestication, fungal brown spot disease, and the future of commercial production in Minnesota. Plant Dis. 76:1193-1197.

Joseph-Horne, T., Hollomon, D. W., and Wood, P. M. 2001. Fungal respiration: A fusion of standard and alternative components. Biochim. Biophys. Acta 1504: 179-195.

Lang, B. F., Laforest, M. J., and Burger, G. 2007. Mitochondrial introns: A critical view. Trends Genet. 23:119-125.

Leiminger, J. H., Adolf, B., and Hausladen, H. 2013. Occurrence of the F129L mutation in Alternaria solani populations in Germany in response to QoI application, and its effect on sensitivity. Plant Pathol. 63:640-650.

Luo, C. X., Hu, M. J., Jin, X., Yin, L. F., Bryson, P. K., and Schnabel, G. 2010. An intron in the cytochrome $\mathrm{b}$ gene of Monilinia fructicola mitigates the risk of resistance development to QoI fungicides. Pest Manag. Sci. 66:1308-1315.

Miguez, M., Reeve, C., Wood, P. M., and Hollomon, D. W. 2004. Alternative oxidase reduces the sensitivity of Mycosphaerella graminicola to QOI fungicides. Pest Manag. Sci. 60:3-7.

Oelke, E. A. 2007. Saga of the grain: A tribute to Minnesota cultivated wild rice growers. Hobar Publications, Lakeville, MN.

Olaya, G., and Köller, W. 1999. Baseline sensitivities of Venturia inaequalis populations to the strobilurin fungicide kresoximmethyl. Plant Dis. 83:274-278.
Pasche, J. S., Piche, L. M., and Gudmestad, N. C. 2005. Effect of the F129L mutation in Alternaria solani on fungicides affecting mitochondrial respiration. Plant Dis. 89:269-278.

Pasche, J. S., Wharam, C. M., and Gudmestad, N. C. 2004. Shift in sensitivity of Alternaria solani in response to QoI fungicides. Plant Dis. 88:181-187.

Pereira, W. V., Primiano, I. V., Morales, R. G. F., Peres, N. A., and May De Mio, L. L. 2017. Reduced sensitivity to azoxystrobin of Monilinia fructicola isolates from Brazilian stone fruits is not associated with previously described mutations in the cytochrome b gene. Plant Dis. 101:766-773.

Reimann, S., and Deising, H. B. 2005. Inhibition of efflux transporter-mediated fungicide resistance in Pyrenophora tritici-repentis by a derivative of $4^{\prime}$ hydroxyflavone and enhancement of fungicide activity. Appl. Environ. Microbiol. 71:3269-3275.

Rosenzweig, N., Olaya, G., Atallah, Z. K., Cleere, S., Stanger, C., and Stevenson, W. R. 2008. Monitoring and tracking changes in sensitivity to azoxystrobin fungicide in Alternaria solani in Wisconsin. Plant Dis. 92:555-560.

Russell, P. E. 2003. Sensitivity baselines in fungicide resistance research and management. FRAC Monogr. No. 3 Cambridge, UK.

Sierotzki, H. 2015. Respiration inhibitors: Complex III. Pages 119-143 in Fungicide Resistance in Plant Pathogens. H. Ishii and D. W. Hollomon, eds. Springer, New York.

Sierotzki, H., Frey, R., Wullschleger, J., Palermo, S., Karlin, S., Godwin, J., and Gisi, U. 2007. Cytochrome b gene sequence and structure of Pyrenophora teres and $P$. tritici-repentis and implications for QoI resistance. Pest Manag. Sci. 63:225-233.

Stammler, G. 2012. Risk of corn pathogens to QoI fungicides. Outlooks Pest Manag. 23:211-214.

Steinfeld, U., Sierotzki, H., Parisi, S., Poirey, S., and Gisi, U. 2001. Sensitivity of mitochondrial respiration to different inhibitors in Venturia inaequalis. Pest Manag. Sci. 57:787-796.

Vallières, C., Trouillard, M., Dujardin, G., and Meunier, B. 2011. Deleterious effect of the Qo Inhibitor compound resistance-conferring mutation G143A in the intron-containing cytochrome $b$ gene and mechanisms for bypassing it. Appl. Environ. Microbiol. 77:2088-2093.

Vincelli, P., and Dixon, E. 2002. Resistance to QoI (strobilurin-like) fungicides in isolates of Pyricularia grisea from perennial ryegrass. Plant Dis. 86: 235-240.

Wood, P. M., and Hollomon, D. W. 2003. A critical evaluation of the role of alternative oxidase in the performance of strobilurin and related fungicides acting at the Qo site of Complex III. Pest Manag. Sci. 59:499-511.

Xu, T., Wang, Y.-T., Liang, W.-S., Yao, F., Li, Y.-H., Li, D.-R., Wang, H., and Wang, Z.-Y. 2013. Involvement of alternative oxidase in the regulation of sensitivity of Sclerotinia sclerotiorum to the fungicides azoxystrobin and procymidone. J. Microbiol. 51:352-358.

Yin, L.-F., Hu, M.-J., Wang, F., Kuang, H., Zhang, Y., Schnabel, G., Li, G.-Q., and Luo, C.-X. 2012. Frequent gain and loss of introns in fungal cytochrome b genes. PLoS One 7:e49096.

Yukioka, H., Inagaki, S., Tanaka, R., Katoh, K., Miki, N., Mizutani, A., and Masuko, M. 1998. Transcriptional activation of the alternative oxidase gene of the fungus Magnaporthe grisea by a respiratory-inhibiting fungicide and hydrogen peroxide. Biochim. Biophys. Acta 1442:161-169.

Ziogas, B. N., Baldwin, B. C., and Young, J. E. 1997. Alternative respiration: A biochemical mechanism of resistance to azoxystrobin (ICIA 5504) in Septoria tritici. Pestic. Sci. 50:28-34. 